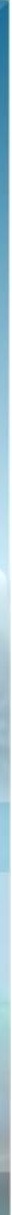




\section{MEDIA FARMASI}

POLITEKNIK KESEHATAN MAKASSAR

\begin{tabular}{lll}
\hline \hline Penasehat & $:$ & Direktur Politeknik Kesehatan Kemenkes Makassar \\
Penanggung Jawab & $:$ & Ketua Jurusan Farmasi Politeknik Kesehatan \\
Dewan Redaksi & & Kemenkes Makassar \\
Manajer & $:$ & Santi Sinala, M.Si.,Apt \\
Editor & $: \quad$ Hendra Stevani, M.Kes.,Apt. \\
& DR.Sisilia Rosmala Dewi M.Kes.,Apt. \\
& Muli Sukmawati, S.Farm.,Apt. \\
& Hesty Setiawati, S.Farm.,M.Si. \\
& Alif Idris,S.Si.,Apt \\
& Jurusan Farmasi Politeknik Kesehatan Makassar \\
& Jl. Baji Gau No.10 Makassar \\
& Telp. 0411-854021, 830883 Fax. 0411-830883 \\
& e-mail : mediafarmasi@ @oltekkes-mks.ac.id \\
Alamat Redaksi & website http://journal.poltekkes- \\
& mks.ac.id/ojs2/index.php/mediafarmasi/ \\
& Kode pos 90134 \\
&
\end{tabular}




\section{EDITORIAL}

Pembaca yang budiman, ucapan syukur Alhamdulillah kami panjatkan ke hadirat Tuhan Yang Maha Kuasa karena berkat rahmat dan anugerahNya sehingga penerbitan Media Farmasi Vol. XV No 2, Oktober 2019 dapat terlaksana dan telah mendapat legalitas sebagai media resmi dari Lembaga Ilmu Pengetahuan Indonesia (LIPI) dengan nomor penerbitan ISSN P. ISSN No. 02162083 E-ISSN 2622-0962 dan telah terakreditasi SINTA Ristekdikti

Media Farmasi Politeknik Kesehatan Makassar merupakan suatu wadah dalam menampung aspirasi ilmiah sehingga dapat menggugah motivasi dan inovasi dari dosen di lingkup Jurusan Farmasi Politeknik Kesehatan Makassar serta artikel dari simpatisan untuk melakukan kajian ilmiah.

Media Farmasi Politeknik Kesehatan Makassar diterbitkan 2 kali dalam setahun yaitu pada bulan April dan Oktober. Sebagai majalah ilmiah, Media Farmasi mengembangkan misi dalam memajukan ilmu pengetahuan dan teknologi kesehatan khususnya di bidang farmasi

Akhirnya redaksi sangat berharap bahwa semua artikel yang disajikan dalam edisi ini dapat memberi apresiasi keilmuan di bidang kesehatan bagi kita semua. Oleh karena itu kritikan dan saran sangat kami harapkan demi kesempurnaan edisi-edisi selanjutnya.

Selamat membaca

Makassar, Oktober 2019

Redaksi 


\section{DAFTAR ISI}

AKTIVITAS ANTIBAKTERI KOMBINASI EKSTRAK DAUN KEMANGI DAN DAUN BINAHONG TERHADAP Streptococcus mutans

Isnaeni Usman, Jane Stefany Rambung, Ermi Reski Hijriah AR, Ismail Ismail

ESCHERICHIA COLI PADA CINCAU HITAM DI PASAR KATANGKA KOTA MAKASSAR

Dedy Maruf, Taufiq Dalming, Ifnur Ayu Fatimah Dinar

AKTIVITAS LARVASIDA EKSTRAK KULIT JERUK PURUT ( CITRUS HYSTRIX D.C.) TERHADAP LARVA NYAMUK

Dwi Rachmawati, Megawati Megawati, Tahir Ahmad

FORMULASI LIPCREAM EKSTRAK DAUN TEH HIJAU (Camelia Sinensis L)

Taufiq Dalming, Ira Widya Sari, Faulata Ainarti Agus

KANDUNGAN RHODAMIN B PADA SEDIAAN LIP TINT YANG DIGUNAKAN MAHASISWI STIKES PELAMONIA

A Asmawati, Desi Reski Fajar, Tuti Alawiyah

FORMULASI PASTA GIGI DARI EKSTRAK ETANOL DAUN BINAHONG (Anredera cordifolia (Ten.) Steenis) DENGAN Natrii carboxymethylellulosum SEBAGAI PENGENTAL

PENGELOLAAN OBAT PROLANIS PASIEN BPJS KESEHATAN DI APOTEK SANA FARMA MAKASSAR PADA PERIODE TAHUN 2018-2019

COST MINIMIZATION ANALYSIS (CMA) PENGGUNAAN AMOKSILIN DAN CEFADROXIL TERHADAP DANA KAPITASI UNTUK ISPA PADA BALITA

EFEK SARI BUAH KERSEN (Muntingia calabura L.) TERHADAP PENURUNAN KADAR GULA DARAH MENCIT (Mus musculus)

FORMULASI DAN EFEK ANTI BAKTERI SEDIAAN GEL PENCUCI TANGAN DARI MINYAK ATSIRI DAUN KEMANGI (Occimum basilicum L.) TERHADAP Eschericia coli

Arisanty Arisanty, Tajuddin Abdullah, Muli Sukmawaty

FORMULASI MASKER PEEL OFFEKSTRAK ETANOL KULIT BUAH NAGA MERAH (HYLOCEREUS POLYRHIZUS) MENGGUNAKAN POLIVINIL ALKOHOL (PVA) 
EFEKTIVITAS EKSTRAK BUNGA JANTAN SUKUN (Artocarpus altis) TERHADAP Streptococcus mutans PENYEBAB KARIES GIGI

Muhdar Latif, Suherman Baharuddin, Dewi Isnaeni, Zulkifli

Formulasi Hand Sanitizer dari Ekstrak Biji Pangi (Pangium edule Reinw) 



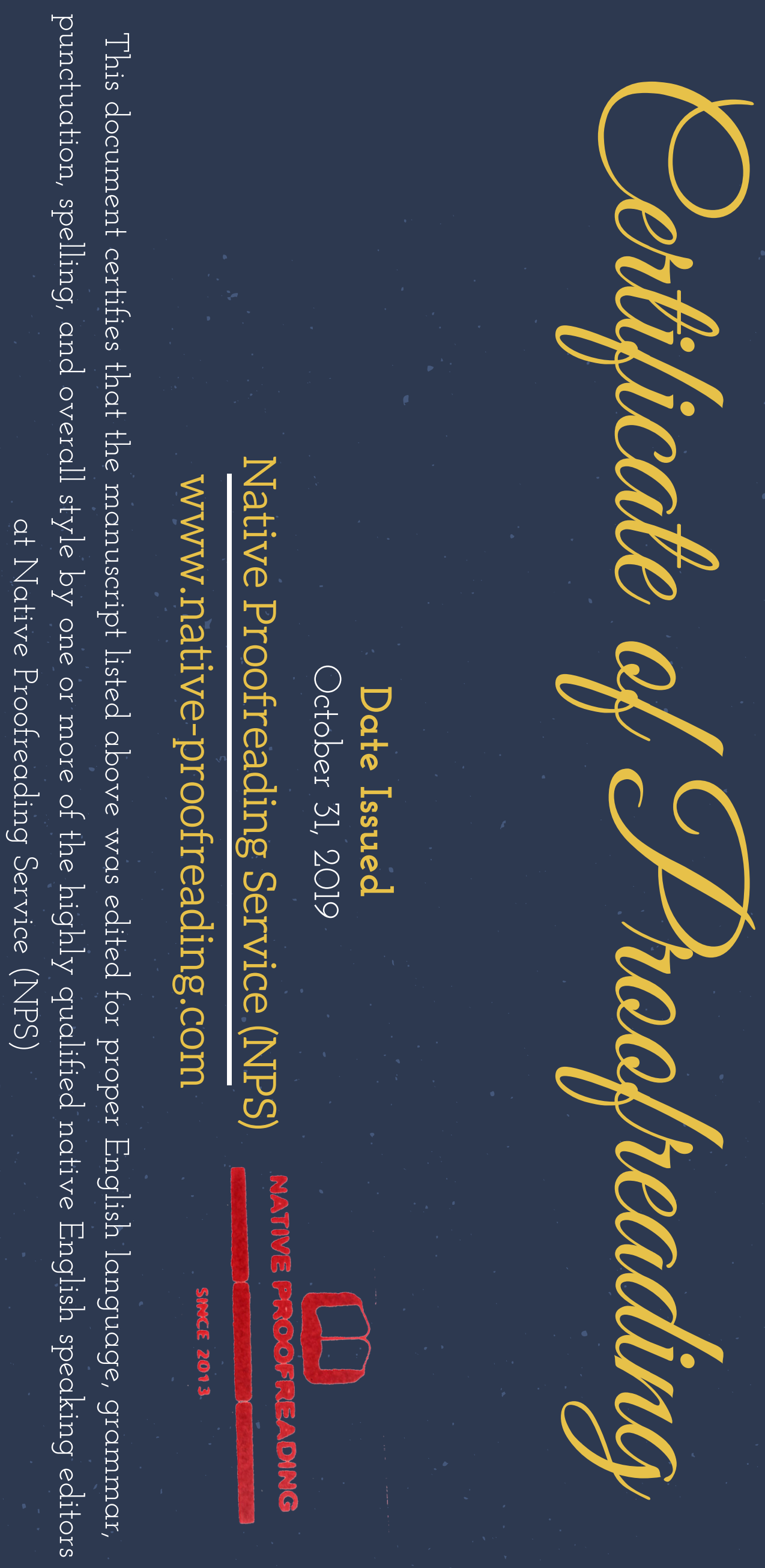

[T]

• 


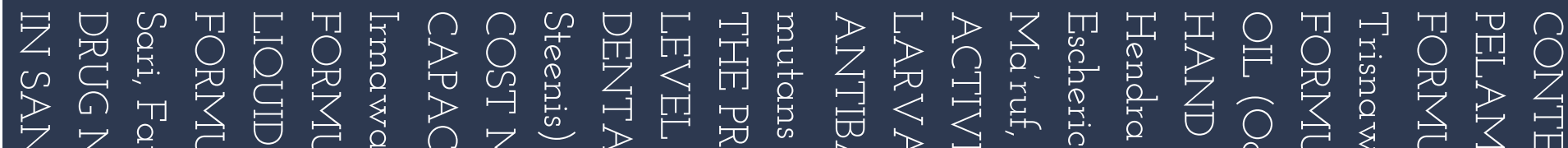

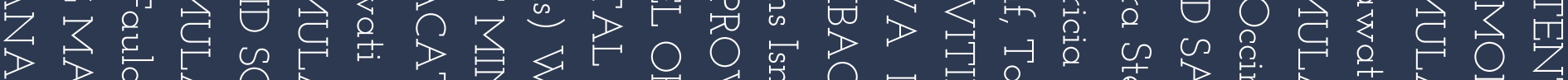

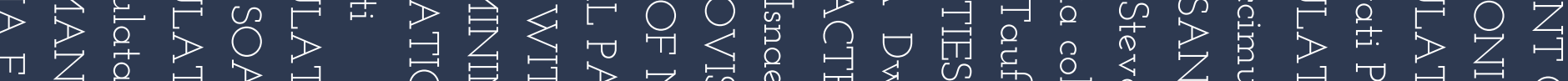

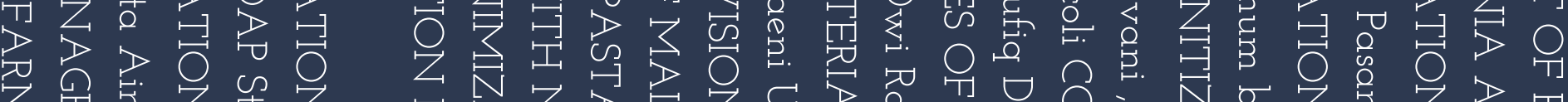
员点

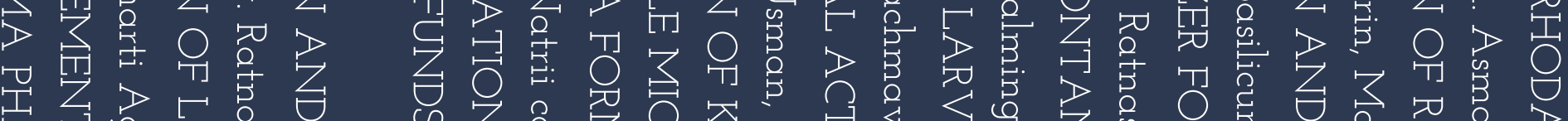

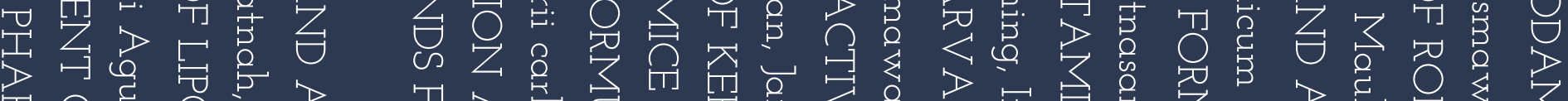

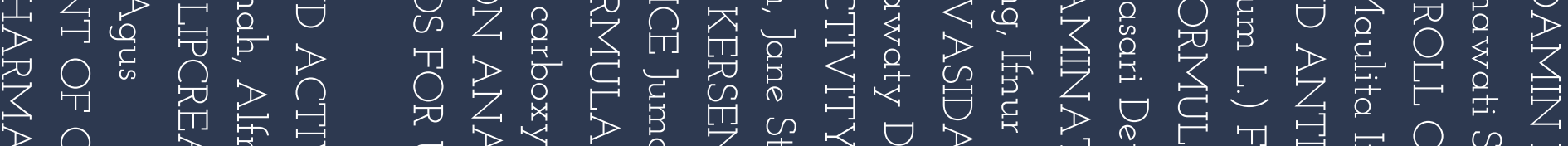

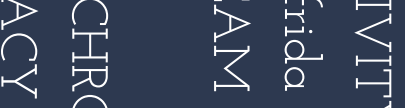

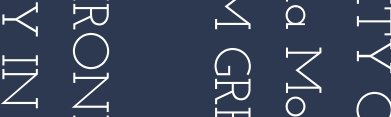
々

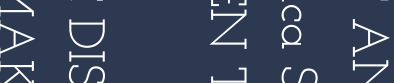

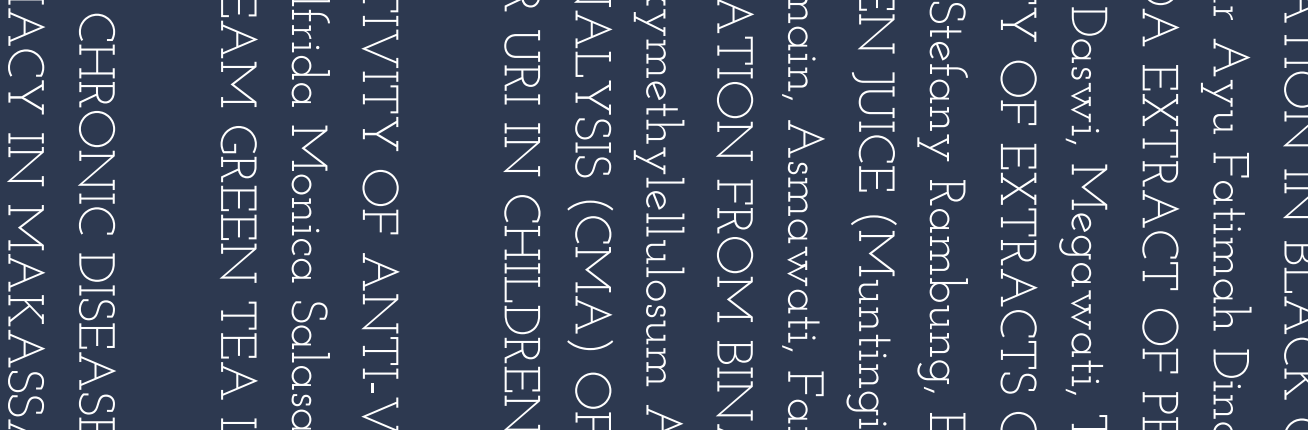

T.

0 Z

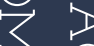

는

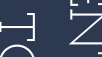

$\stackrel{0}{0}$

?

号

?

P

ঔ

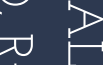

至

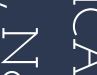

O

$\ll \omega_{0}$

مै'

气

呵

$Z$

范
ए门, 0

$>\quad$ 口

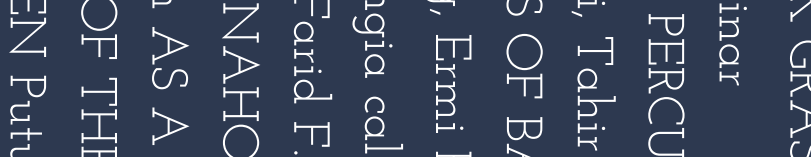

Tा

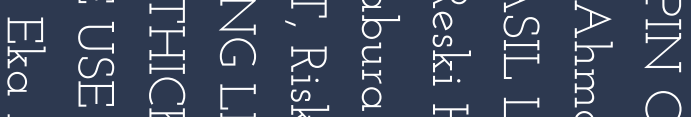

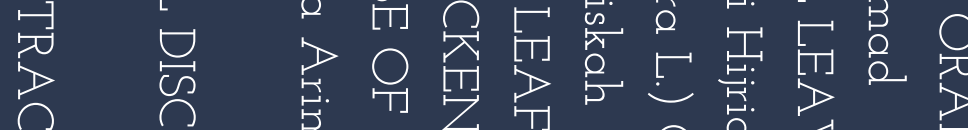

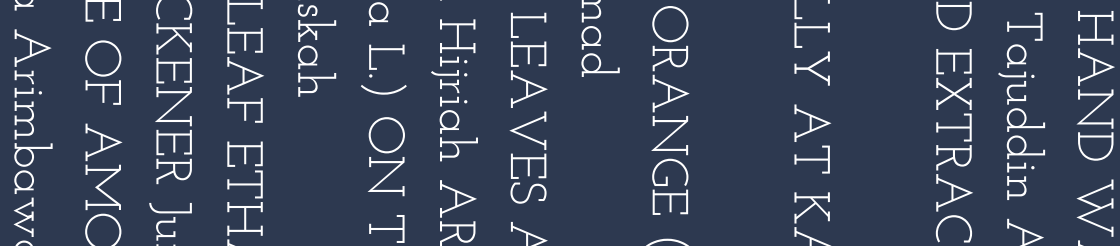

量.

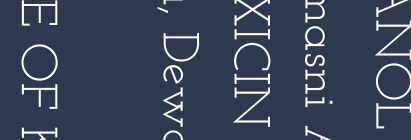

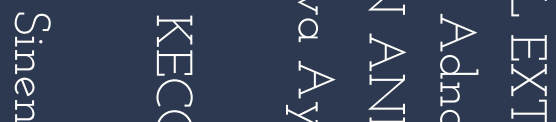

○一

曰

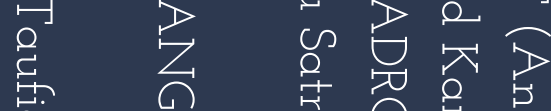

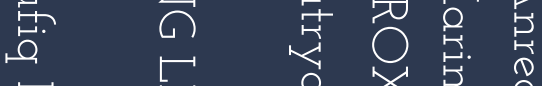

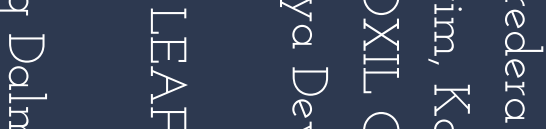

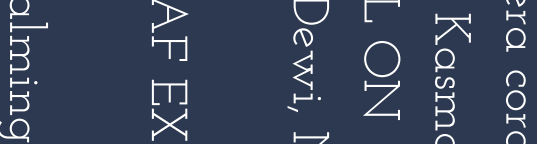

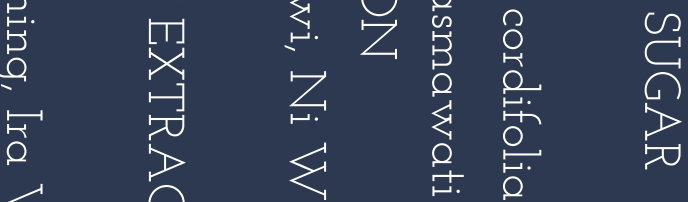

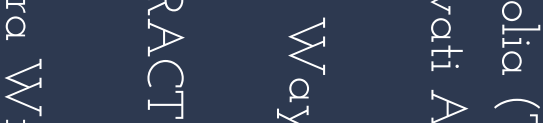

$\stackrel{+}{\stackrel{2}{0}}$

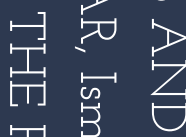

开

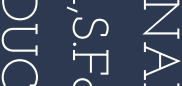

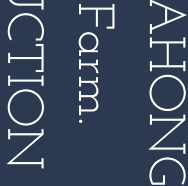

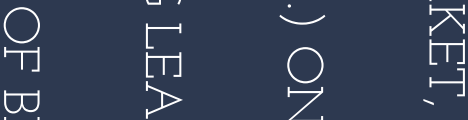

8 ता<smiles>C1CC1</smiles>

C

T.

[

อ ?

点

它.

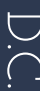

$\because \quad$ 苗

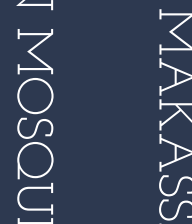

马

$\underset{\sim}{\mathcal{B}}$

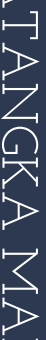

莡

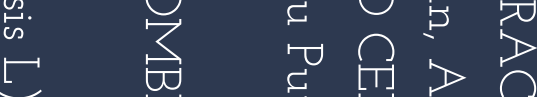

T

$\gg \bigcirc$ एक

$\bigcirc$ 雨

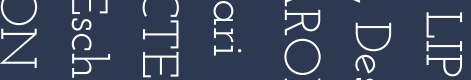

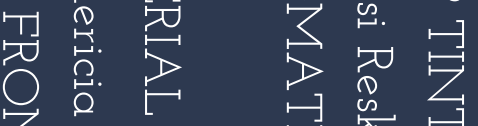

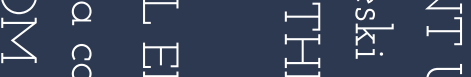

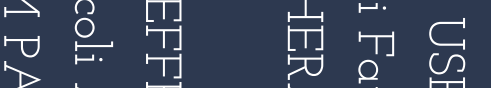
马界 $\gg \frac{0}{0}$

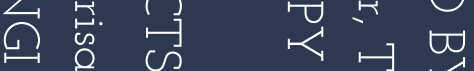
ल

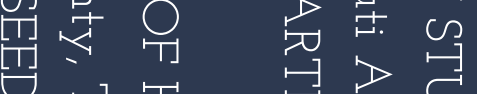

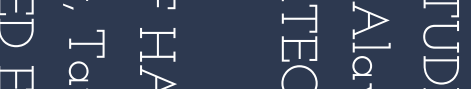

त

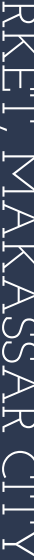

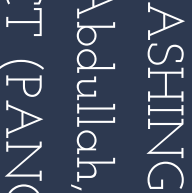

\&

点范

$\bigoplus \stackrel{0}{\forall}$

⿶

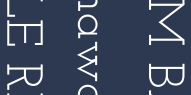

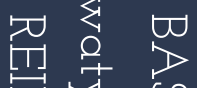

要幦

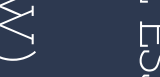

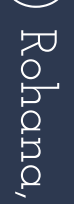

零 点思 Z

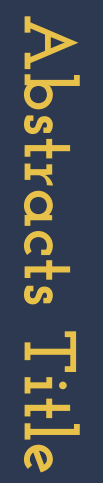

?

点

O1

'T 需

岕点

ह ए

(s)

음

ค1] 


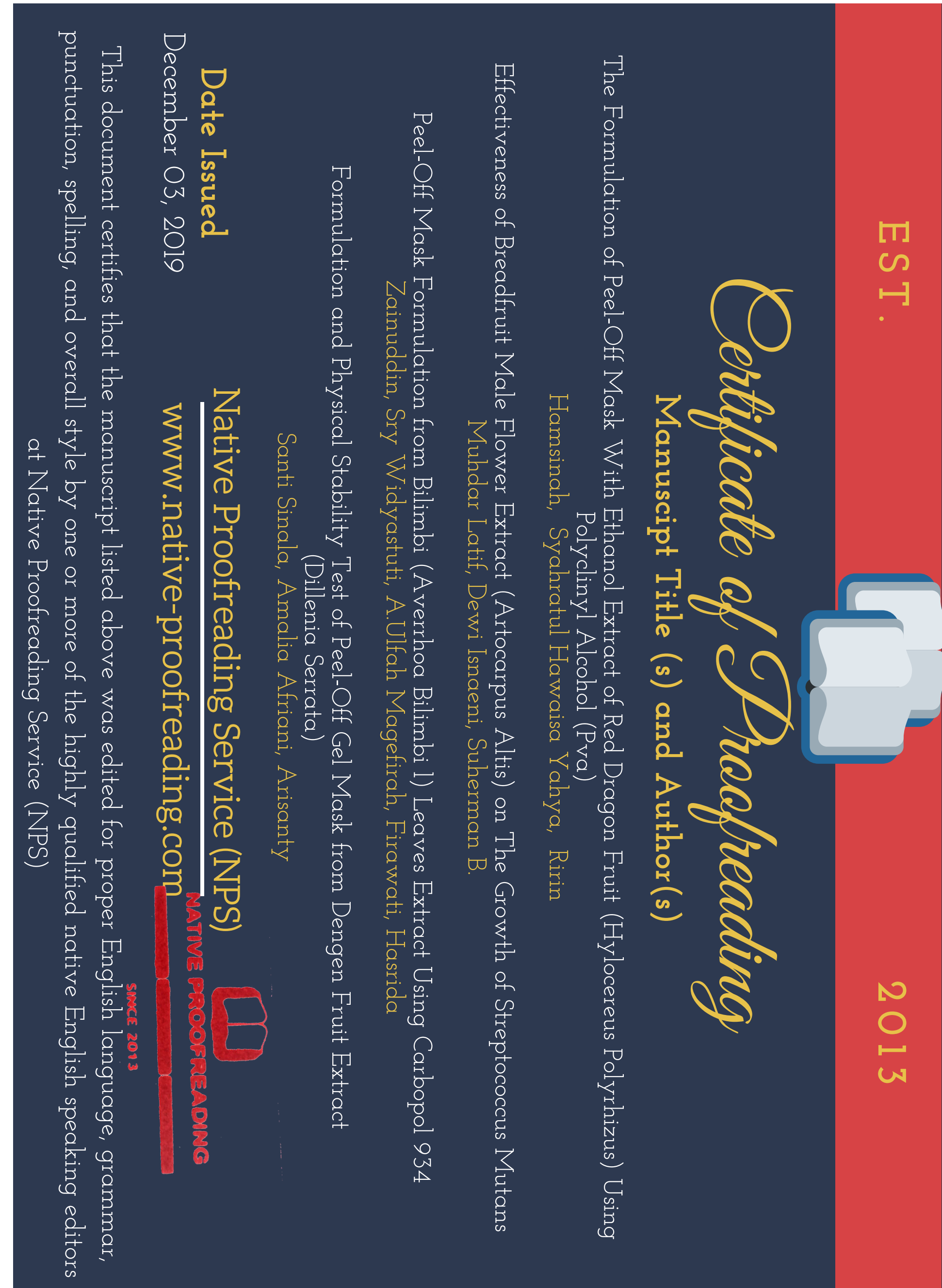

